\title{
Role of exotoxin A in inducing severe Pseudomonas aeruginosa infections in mice
}

\author{
SHUICHI MIYAZAKI, TETSUYA MATSUMOTO, KAZUHIRO TATEDA, AKIRA OHNO \\ and KEIZO YAMAGUCHI
}

Department of Microbiology, Toho University School of Medicine, Omori-nishi 5-21-16, Ota-ku, Tokyo 143, Japan

\begin{abstract}
Summary. The effects of exotoxin A (EXA) from Pseudomonas aeruginosa on polymorphonuclear leucocytes (PMNLs) were studied in a mouse model and in vitro. P. aeruginosa PA103, which produced EXA, was 20 times more virulent for normal mice than was its EXAdeficient mutant, PA103-29. EXA was detected in the plasma of mice infected with $P$. aeruginosa PA103, and its presence correlated with increasing numbers of bacteria in the blood and internal organs. A monoclonal antibody (MAb) against EXA prevented the death of the mice if it was given simultaneously with, or $2 \mathrm{~h}$ before, infection with strain PA103. The number of PMNLs in murine blood decreased by $50 \%$ within $30 \mathrm{~min}$ of intravenous injection of EXA, but this decrease was prevented by simultaneous or prior injection of MAb to the toxin. EXA inhibited in-vitro phagocytosis and killing of $P$. aeruginosa by human and murine PMNLs and decreased the number of the PMNLs by between 60 and $68 \%$. Collectively, these results not only confirm that EXA is toxic in vivo, but also suggest that this toxin accelerates the growth of virulent $P$. aeruginosa in mice.
\end{abstract}

\section{Introduction}

Pseudomonas aeruginosa is a significant cause of nosocomical infection and has a capacity for tissue invasion, often leading to septicaemia and death. Mortality rate in pseudomonas bacteraemias are higher than in bacteraemias caused by most other gram-negative opportunist pathogens..$^{1-3}$

Exotoxin A (EXA) is a major toxic product of $P$. aeruginosa and contributes to mortality in experimental animals and patients. Its mechanism of action against mammalian cells has been studied in detail. ${ }^{4-11}$ There are reports that the survival rate among patients with antibodies to EXA or the lipopolysaccharide (LPS) of $P$. aeruginosa, or both, are higher than those of patients without these antibodies. ${ }^{5,7}$ Moreover, it has been reported that $80 \%$ of $P$. aeruginosa isolates from infections produce EXA and that the mortality rate among patients infected with isolate producing EXA is three times higher than that among patients infected by non-producers. ${ }^{1}$

We hypothesised that EXA might cause a decrease in the numbers of polymorphonuclear leucocytes (PMNLs), or a disturbance of their function, and that this might accelerate the proliferation of the bacteria, increasing the likelihood of death. To clarify the action of EXA on PMNLs, the changes in bacterial numbers in the blood and internal organs of mice inoculated intraperitoneally with an EXA-producing strain of $P$. aeruginosa or with its EXA-deficient mutant were examined. In addition, the effects of EXA on the function of PMNLs were examined in vitro and in vivo. Finally, the effect of a neutralising antibody, MAb $3 C 7,{ }^{12}$ on the in-vivo and in-vitro actions of EXA on PMNLs was investigated.

\section{Materials and methods}

\section{Organisms}

$P$. aeruginosa PA103, which is virulent for mice, and its non-virulent derivative, PA103-29, were a gift from Dr Igrewski. Both were stored at $-80^{\circ} \mathrm{C}$ in skimmed milk $20 \%$.

\section{Exotoxin A (EXA)}

Pseudomonas EXA was purchased from the Swiss Serum and Vaccine Institute (Berne, Switzerland). It was $>97 \%$ pure and was free of LPS. 


\section{Mouse monoclonal antibodies ( $M A b s$ )}

MAb 3C7 (IgG1), which binds to EXA, was a gift from the Research Laboratories of Sumitomo Pharmaceuticals Ltd (Osaka, Japan). MAb 1B5 (IgG3), to an outer-membrane component of Haemophilus influenzae, was prepared by $\operatorname{Dr} T$. Matsumoto in this laboratory (unpublished).

\section{Animals}

Four week-old male ICR mice, weighing 18-20 g (Japanese Charles River, Atsugi, Japan) were used in groups of 10, unless otherwise indicated. Leucopenia was induced by treatment with a single intraperitoneal (i.p.) dose of cyclophosphamide (Sigma) of 250 $\mathrm{mg} / \mathrm{kg}$, given 4 days before bacterial challenge. ${ }^{13}$

\section{Preparation of inocula for infection}

Bacteria were cultured overnight on Nutrient Agar (Difco) at $35^{\circ} \mathrm{C}$, then harvested, washed twice and resuspended in saline to an $\mathrm{OD}_{660}$ of $0 \cdot 2$, corresponding to c. $3 \times 10^{8} \mathrm{cfu} / \mathrm{ml}$. Doubling dilutions of this suspension were employed for i.p. injection. To confirm the inoculum size, plate counts were determined in duplicate on serial dilutions of the suspensions. ${ }^{14}$

\section{LD50 determinations}

Mice were challenged with a single i.p. injection of $0.5 \mathrm{ml}$ of the bacterial suspension. Eight dilutions, containing different numbers of viable bacteria, were used to determine LD50 values, and mortality was assessed daily for 5 days after infection.

\section{Protection by $M A$ Ab to EXA against $P$. aeruginosa infection in mice}

The method of Kohzuki et al. was followed. ${ }^{15}$ Groups of mice were given MAb $3 \mathrm{C} 7$ intravenously (i.v.) at a dose of $10 \mu \mathrm{g} /$ mouse either simultaneously with, $2 \mathrm{~h}$ before or $2 \mathrm{~h}$ after, infection with $1.5 \times 10^{6}$ $\mathrm{cfu} /$ mouse of $P$. aeruginosa cells. A control group of mice was challenged with the same inoculum of bacteria but without MAb $3 \mathrm{C} 7$.

\section{Quantitation of bacteria in mice and estimation of $E X A$ and $L P S$}

Mice, in groups of five, were challenged by i.p. injection with $0.5-\mathrm{ml}$ portions of bacterial suspensions. The challenge dose was $1.6 \times 10^{7} \mathrm{cfu} /$ mouse of the virulent strain PA103 or $1.3 \times 10^{8} \mathrm{cfu} /$ mouse of the avirulent strain PA103-29. Samples were obtained at 2, 4 and $6 \mathrm{~h}$ after infection; the mice were anaesthetised with diethyl ether. Blood was obtained by heart puncture with a disposable heparinised syringe and, simultaneously, the liver, spleen, kidneys and lung were removed, homogenised (Homogenizer, Hongoikakikai, Tokyo, Japan) and diluted in saline. The samples and their dilutions were plated in dupli- cate on nutrient agar for viable counts. ${ }^{14}$ Portions of the blood samples also were centrifuged, and the supernates were assayed for EXA and LPS. EXA was measured by ELISA (according to Kohzuki et al. ${ }^{15}$ ), which has a lower detection limit of $2 \mathrm{ng} / \mathrm{ml}$, and LPS was assayed by the chromogenic Limulus test (Toxicolor system; Seikagaku Co., Tokyo, Japan), ${ }^{\mathbf{1 6}}$ which has a lower detection limit of $0.3 \mathrm{ng} / \mathrm{ml}$.

\section{Influence of purified EXA on PMNLs}

Mice, in groups of five, were inoculated i.v. with either $0.1 \mathrm{ml}$ of EXA $1 \mu \mathrm{g} / \mathrm{ml}$ in saline or with a mixture containing EXA $1 \mu \mathrm{g} / \mathrm{ml}$ plus either MAb $3 \mathrm{C} 7$ or MAb 1 B5 $100 \mu \mathrm{g} / \mathrm{ml}$. At 0.5, 1, 2 and $24 \mathrm{~h}$ after injection, the mice were lightly anaesthetised with diethyl ether and $30-\mu$ samples of blood were removed from the retro-orbital plexus with disposable, heparinised, capillary tubes. These samples were stained with Turk solution for determination of white blood cell numbers or with May-Grünwald-Giemsa stain for PMNL counts.

\section{Interactions of PMNLs and EXA in vitro}

Mouse PMNLs were prepared as described elsewhere, ${ }^{17}$ and suspended at a density of $1.0 \times 10^{7} / \mathrm{ml}$ in Eagle's Minimal Essential Medium (MEM; Gibco Laboratories, Grand Island, NY, USA). Human PMNLs were purified from human peripheral blood by Hypaque-Ficoll (Flow Laboratories, Irvine) ${ }^{18}$ and resuspended in MEM at the same density as the mouse PMNLs. A $0 \cdot 1$-ml-portion of EXA solution, $2 \mu \mathrm{g} / \mathrm{ml}$ in MEM, with or without MAb 3C7 at $200 \mu \mathrm{g} / \mathrm{ml}$, was added to $0.9 \mathrm{ml}$ of the human or mouse PMNLs and the mixture was rotated at $5 \mathrm{rpm}$ for $1 \mathrm{~h}$ at $35^{\circ} \mathrm{C}$. One $\mathrm{ml}$ of bacterial suspension $\left(1.0 \times 10^{6} \mathrm{cfu} / \mathrm{ml}\right)$ in $\mathrm{MEM}$, containing fresh human or mouse serum $10 \%$, was then added, and after rotation for a further $2 \mathrm{~h}$, each sample was plated in duplicate on nutrient agar for viable counts. ${ }^{14}$ In addition, the PMNLs were counted in a haemocytometer and their morphology was examined by microscopy after staining by the MayGrünwald-Giemsa method.

\section{Data analysis}

The LD50 of the bacteria was calculated by probit analysis from the survival rates of the mice after 5 days of infection. ${ }^{19}$ Numbers of organisms and PMNLs in different groups of animals were compared by Student's $t$ test.

\section{Results}

Virulence of P. aeruginosa PA103 and PA103-29 in mice

The LD50s of $P$ aeruginosa PA103 and PA103-29 in normal mice were $6.82 \times 10^{5}$ and $1.36 \times 10^{7} \mathrm{cfu} / \mathrm{mouse}$, 
a

b
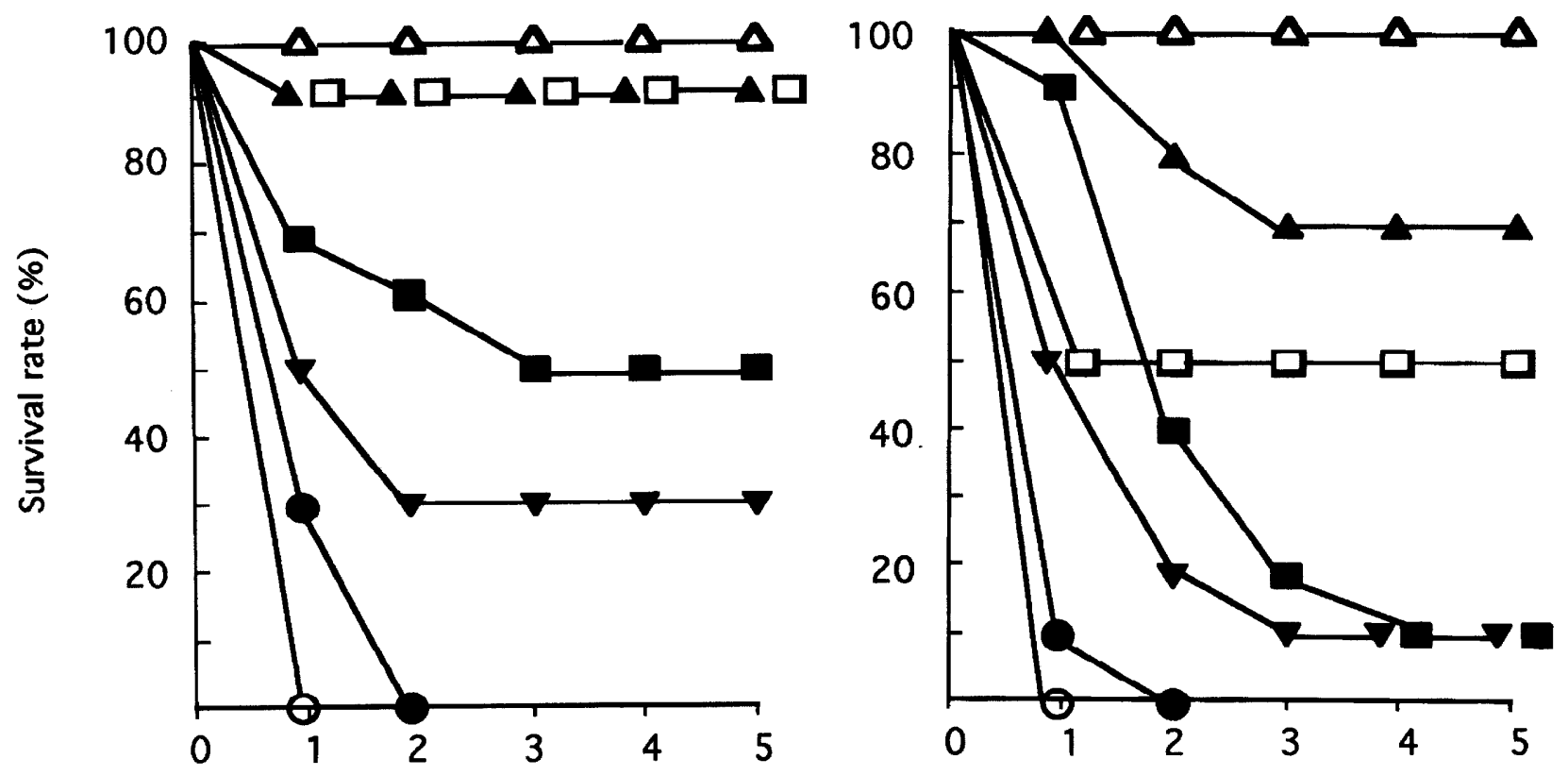

Time after infection (days)

Fig. 1. Survival of mice infected with $P$. aeruginosa PA103 or PA103-29. a, In normal mice the challenge dose of $P$. aeruginosa PA103 was $1.26 \times 10^{7}(\mathbf{O}), 2.52 \times 10^{6}(\nabla), 5.04 \times 10^{5}(\mathbf{\square})$ or $1.01 \times 10^{5}(\mathbf{\Delta}) \mathrm{cfu} / \mathrm{mouse}$ and that of $P$. aeruginosa PA103-29 was $2.72 \times 10^{7}(\mathrm{O}), 5.44 \times 10^{6}$ $(\square)$ or $1.09 \times 10^{6}(\triangle)$; b, in neutropenic mice that of $P$. aeruginosa PA103 was $5.04 \times 10^{5}(\mathbf{O}), 1.01 \times 10^{5}(\boldsymbol{\nabla}) 2.02 \times 10^{4}(\mathbf{\square})$ or $4.03 \times 10^{3}(\mathbf{\Delta})$ and that of $P$. aeruginosa PA103-29 was $2.72 \times 10^{7}(O), 5.44 \times 10^{6}(\square)$ or $1.09 \times 10^{6}(\triangle)$. Ten mice were used in each group.
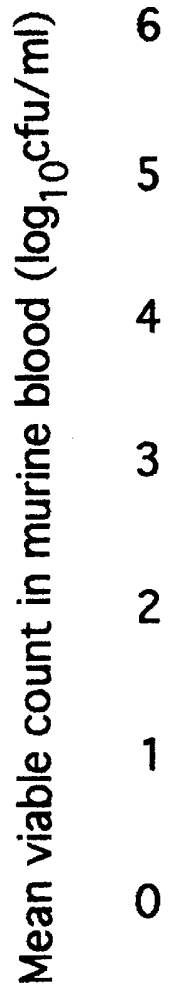

0

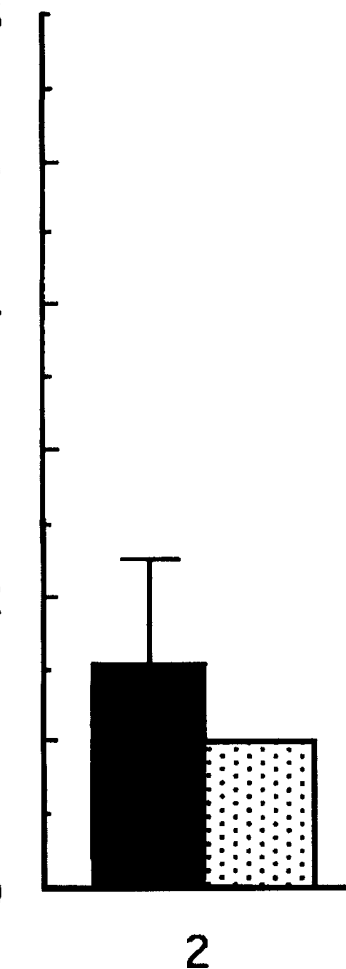

2

4

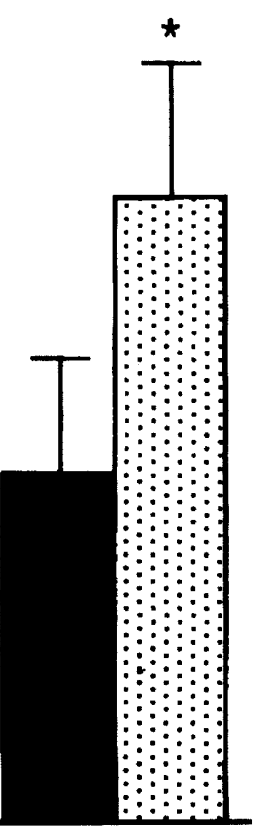

6

Time after infection (h)

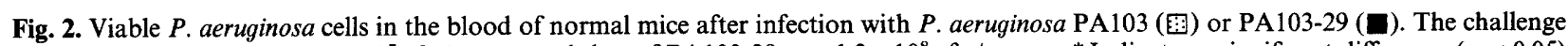
dose of strain PA103 was $1.6 \times 10^{7} \mathrm{cfu} /$ mouse and that of PA103-29 was $1.3 \times 10^{8} \mathrm{cfu} /$ mouse. ${ }^{*}$ Indicates a significant difference $(\mathrm{p}<0.05)$ between the results for the two organisms; bars indicate SD. 
a

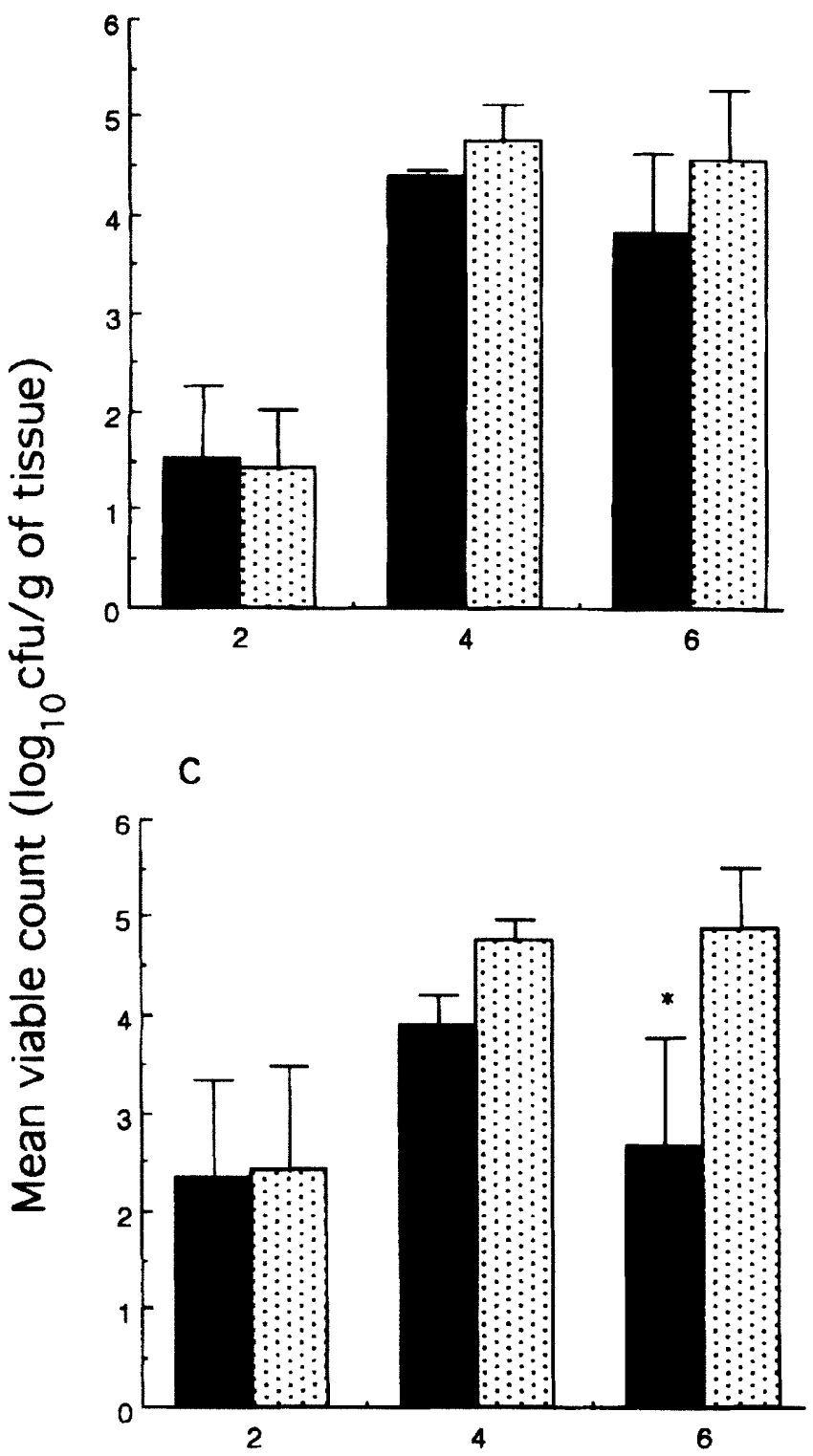

b

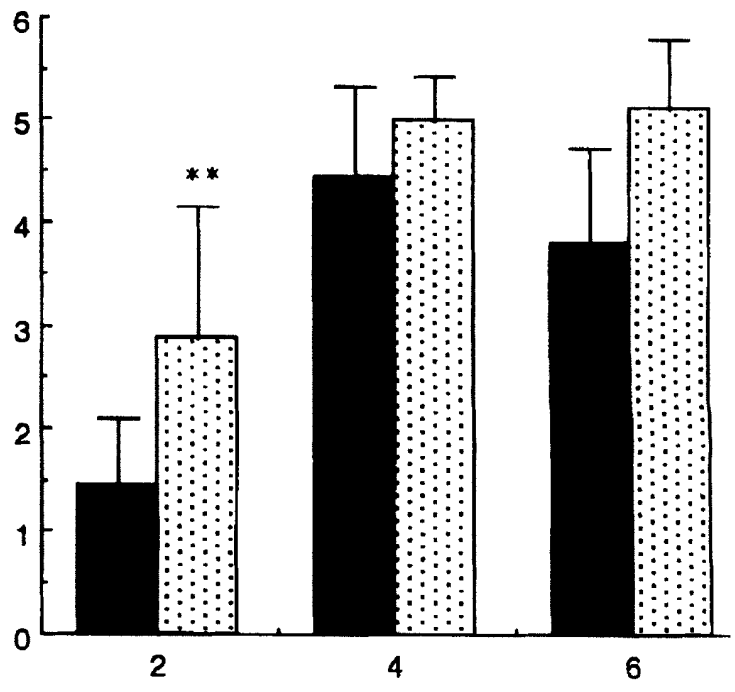

d

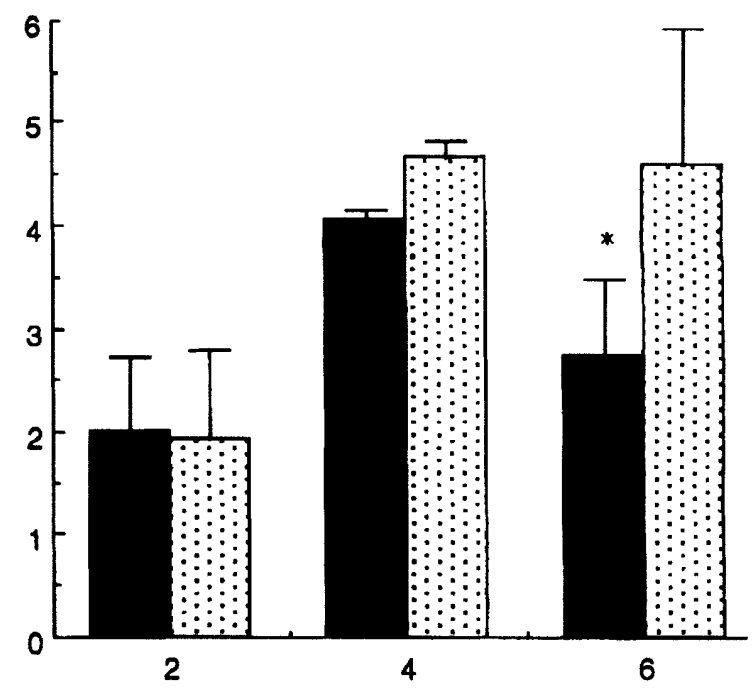

\section{Time after infection (h)}

Fig. 3. Viable counts of $P$. aeruginosa in a: lungs; b, livers; $\mathbf{c}$, spleens; $\mathbf{d}$, kidneys of normal mice after infection with $P$. aeruginosa $P A 103$ (D) or strain PA103-29(a). The challenge doses were as shown in fig. $2 .{ }^{*}$ Indicates a significant difference at $\mathrm{p}<0.01$ and $* *$, at $\mathrm{p}<0.05$, between the results for the two organisms; bars indicate SD.

respectively, whereas those in neutropenic mice were $8.40 \times 10^{3}$ and $6.03 \times 10^{6}$, respectively (fig. 1). Thus, the virulence of $P$. aeruginosa PA103 in the neutropenic mice was 151-fold greater than in normal mice, whereas the virulence of $P$. aeruginosa PA103-29 was only double that in normal mice. Normal and neutropenic mice infected with $P$. aeruginosa PA103 died between 1 and 4 days after infection, whereas deaths among mice infected with strain PA103-29 occurred only on the first 2 days after infection.

When MAb $3 \mathrm{C} 7$ was given simultaneously with, or $2 \mathrm{~h}$ before, infection with $1.50 \times 10^{6} \mathrm{cfu} /$ mouse of $P$. aeruginosa PA103, the survival rates of the mice were $70 \%$ and $80 \%$, respectively. However, only $40 \%$ of the mice survived when the antibody was given $2 \mathrm{~h}$ post-infection, no more than when the mice were not given the antibody.

\section{Localisation of bacteria in infected mice}

The bacterial numbers in blood samples taken at various times after infection were examined. At 2 and $4 \mathrm{~h}$ after infection, the mean numbers of $P$. aeruginosa PA103-29 cells were more than those of $P$. aeruginosa PA103, reflecting the fact that the challenge dose of the former, avirulent, organism was about 10 -fold greater than that of the latter, virulent, strain (fig. 2). However, by $6 \mathrm{~h}$ after infection the mean bacterial numbers in the blood of mice infected with $P$. aeruginosa PA103 were $>10$-fold greater than those from mice infected 

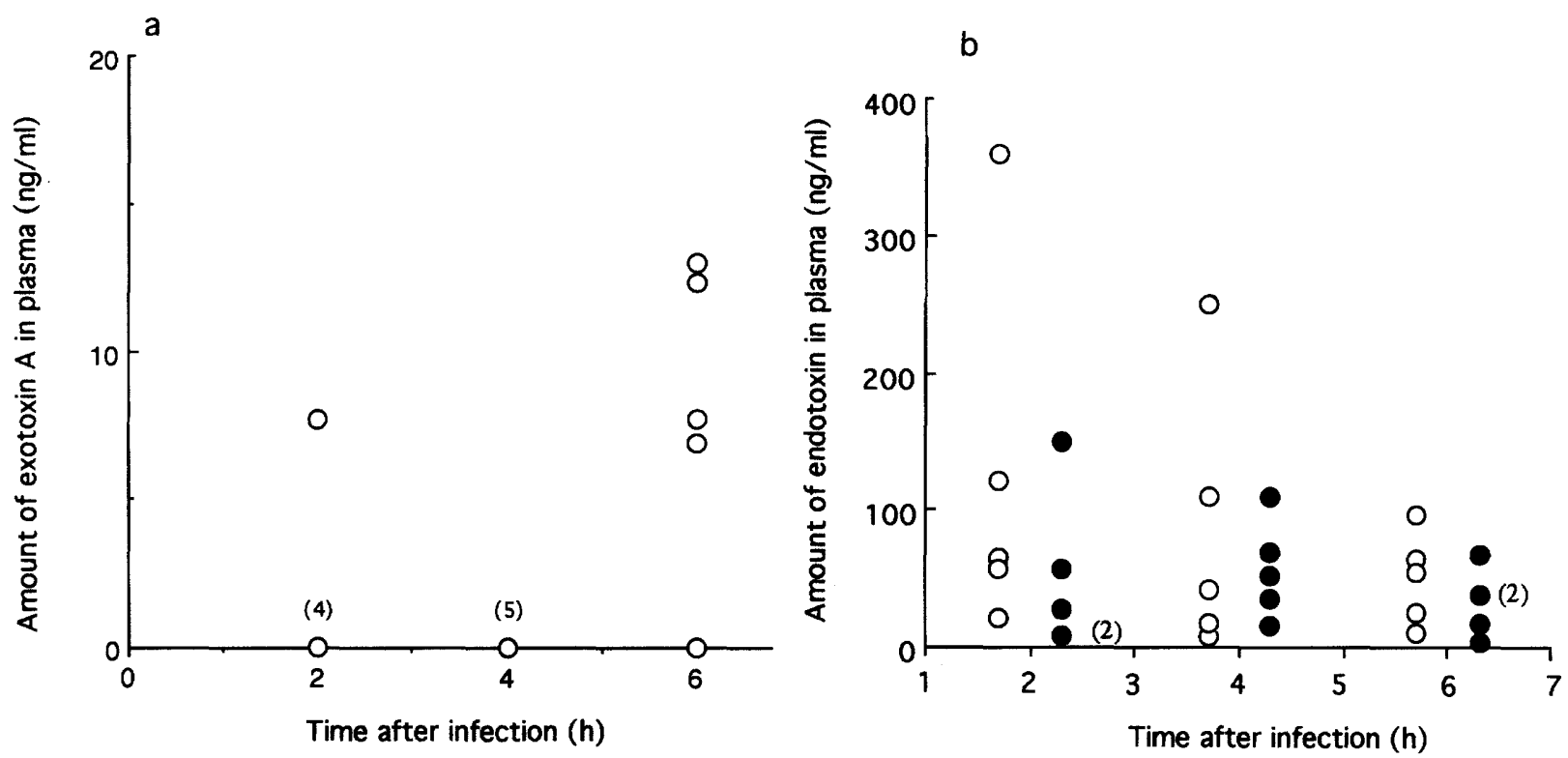

Fig. 4. Levels of: a, EXA; b, LPS in the plasma of mice after infection with $P$. aeruginosa PA103 (O) or PA103-29 (O). The challenge doses were as shown in fig. 2. Numbers in brackets indicate when identical results were obtained for more than one mouse.

with $P$. aeruginosa PA103-29. This difference was significant $(\mathrm{p}<0.05)$.

Bacterial numbers in the liver, lungs, spleen and kidneys were also examined (fig. 3). At $2 \mathrm{~h}$ after infection, the mean bacterial counts from the livers of mice infected with $P$. aeruginosa PA103 were significantly $(\mathrm{p}<0.05)$ greater than in those of mice infected with $P$. aeruginosa PA103-29 (fig. 3b). $P$. aeruginosa PA103 proliferated rapidly, reaching $c .10^{5}$ $\mathrm{cfu} / \mathrm{g}$ in all tissues examined by $4 \mathrm{~h}$ after infection, but with little further change by $6 \mathrm{~h}$ after infection. However, with $P$. aeruginosa PA103-29, the number of organisms in each organ peaked around $4 \mathrm{~h}$ after infection, at $c .10^{4} \mathrm{cfu} / \mathrm{g}$, and tended to decline over the next $2 \mathrm{~h}$, especially in the spleen and kidneys where the counts at $6 \mathrm{~h}$ reduced to $10^{2} \mathrm{cfu} / \mathrm{g}$ of tissue (fig. $3 \mathrm{c}, \mathrm{d})$. These 6 -h counts were significantly below those recorded in mice infected with $P$. aeruginosa PA103 $(\mathrm{p}<0.01)$.

\section{Concentrations of EXA and LPS in plasma}

Only one of five mice infected with strain PA103 had a measurable EXA level at $2 \mathrm{~h}$ after infection (fig. $4 \mathrm{a}$ ), but four of five infected mice had measurable levels by $6 \mathrm{~h}$ after infection, ranging from 6.9 to $13 \mathrm{ng} / \mathrm{ml}$. EXA was not detected in mice infected with $P$. aeruginosa PA103-29. The plasma concentrations of LPS were almost identical in mice infected with either $P$. aeruginosa PA103 or its mutant by $6 \mathrm{~h}$ after infection (fig. $4 b$ ).

\section{The effects of EXA on PMNLs in vivo}

The mean number of PMNLs in blood from normal mice was 1420 (SD 117) cells $/ \mathrm{mm}^{3}$, but this was significantly reduced $(\mathrm{p}<0.05)$ by $0.5-2 \mathrm{~h}$ after injection of EXA alone (fig. 5). This reduction did not occur in mice given a mixture of EXA and the homologous antibody $\mathrm{MAb} 3 \mathrm{C} 7$, but was still observed when EXA was given with the non-homologous antibody, MAb 1B5. No significant differences in the numbers of PMNLs in the blood remained by $24 \mathrm{~h}$ after injection of EXA.

\section{Effect of EXA on bacterial phagocytosis and killing by PMNLS}

When $P$. aeruginosa PA103 cells, at an initial density of $5 \times 10^{5}$, were incubated for $2 \mathrm{~h}$ with fresh human serum, with or without human PMNLs, the bacterial counts were $1.82 \times 10^{4}$ and $4.79 \times 10^{5}$, respectively (table I). Addition of EXA reduced the extent of bacterial killing by the PMNLs, but killing was partially regained if $\mathrm{MAb} 3 \mathrm{C} 7$ was also added. $P$. aeruginosa PA103-29 was also killed by human PMNLs and, once again, this killing was reduced if EXA was added $(p<0.01)$, but substantially recovered when MAb $3 C 7$ also was present $(p<0 \cdot 01)$.

The decreases in bacterial numbers achieved by murine PMNLs in murine serum were smaller than those obtained by human PMNLs in human serum, but the pattern of the results was almost identical. After incubation with serum-treated bacteria and EXA for $2 \mathrm{~h}$, the numbers of human and murine PMNLs were decreased to $60 \%$ and $68 \%$ of their starting numbers, respectively. The destroyed PMNLs, and their swollen nuclei, were observed by microscopy after staining by the May-Grünwald-Giemsa method.

\section{Discussion}

Woods and Iglewski ${ }^{8}$ found significantly higher LD50 values for the toxin-deficient $P$. aeruginosa mutants, PA103-29 and PAO-T1, than for their 


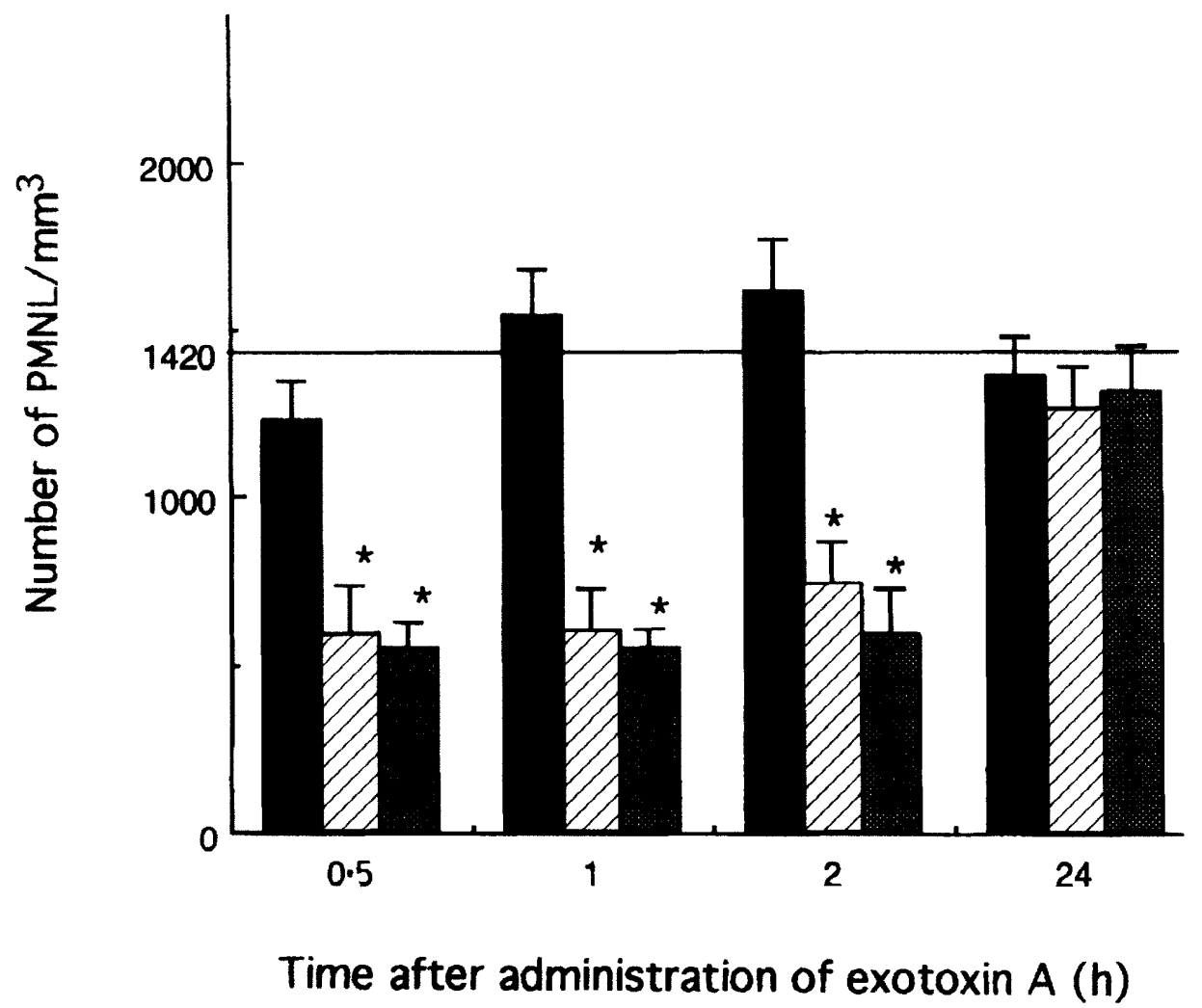

Fig. 5. Mean number (and SD) of PMNLs in peripheral streaming blood in mice. $\square$, mice given EXA alone; $\mathbf{a}$, mice given EXA plus MAb $3 \mathrm{C} 7$; 曲, mice given EXA plus MAb 1B5. * Indicates $\mathrm{p}<0.01$, compared to control mice and those given EXA plus MAb $3 C 7$.

Table I. Effects of EXA on the phagocytosis and killing P. aeruginosa by murine and human PMNLs

\begin{tabular}{|c|c|c|c|}
\hline \multirow[b]{2}{*}{ Organism } & \multirow{2}{*}{$\begin{array}{l}\text { Additions to the mixture } \\
\text { of bacteria and serum }\end{array}$} & \multicolumn{2}{|c|}{$\begin{array}{l}\text { Viable bacteria* after incubation } \\
\text { for } 2 \mathrm{~h}\left(\log _{10} \mathrm{cfu} / \mathrm{ml}\right)\end{array}$} \\
\hline & & mouse PMNLs & human PMNLs \\
\hline $\begin{array}{l}\text { P. aeruginosa } \\
\text { PA } 103\end{array}$ & $\begin{array}{l}\text { None } \\
\text { PMNLs } \\
\text { PMNLs + EXA } \\
\text { PMNLs + EXA + MAb 3C7 }\end{array}$ & $\begin{array}{l}5.42(0.25) \\
5.09(0.04) \dagger \ddagger \\
5.39(0.03) \\
5 \cdot 12(0.04) \dagger \ddagger\end{array}$ & $\begin{array}{l}5.68(0.05) \\
4.26(0.03) \dagger \dagger \\
5.29(0.03) \dagger \\
4.88(0.09) \dagger+\end{array}$ \\
\hline $\begin{array}{l}\text { P. aeruginosa } \\
\text { PA } 103-29\end{array}$ & $\begin{array}{l}\text { None } \\
\text { PMNLs } \\
\text { PMNLs + EXA } \\
\text { PMNLs + EXA + MAb 3C7 }\end{array}$ & $\begin{array}{l}5.51(0.12) \\
5.06(0.08) \S \\
5.41(0.04) \\
5.15(0.21) \S\end{array}$ & $\begin{array}{l}5 \cdot 30(0.05) \\
4.81(0 \cdot 49) \S \\
5 \cdot 27(0.09) \\
5 \cdot 04(0.02) \S\end{array}$ \\
\hline
\end{tabular}

\footnotetext{
* Mean (SD) of three separate experiments.

$\dagger \mathrm{p}<0.01$ as compared to None versus $P$. aeruginosa PA103.

$\ddagger \mathrm{p}<0.01$ as compared to PMNLs+EXA versus P. aeruginosa PA103.

$\S \mathrm{p}<0.01$ as compared to None or PMNLs + EXA versus P. aeruginosa PA103-29.
}

corresponding toxigenic parent strains, PA103 and PAO-1. In the case of strain PA103-29, EXA was absent, or produced at a vastly lower level, than in strain PA103. ${ }^{20}$ It is well known that EXA inhibits protein synthesis in mammalian cells by transferring the ADP-ribose moiety of $\mathrm{NAD}^{+}$to elongation factor II, leading to tissue damage and cell death. ${ }^{12}$ EXA is one of the most powerful exotoxins of $P$. aeruginos $a^{6}$ and levels of antibody to EXA were higher in patients who survived $P$. aeruginosa bacteraemias than in those who died of their infection. ${ }^{1}$ Pollack and Young ${ }^{5}$ showed that the amount of antibody to EXA correlated well with the survival rate among patients with $P$. aeruginosa bacteraemia.
The present study confirmed that the virulence of $P$. aeruginosa PA103 was greater than that of strain PA103-29 in both normal and neutropenic mice. Mice infected with strain PA103-29 only died if at all from bacteraemia within 2 days, whereas those infected with strain PA103 died in greater numbers not only within the first 2 days but also later. The presence of neutropenia enhanced the virulence of $P$. aeruginosa PA103 much more than that of $P$. aeruginosa PA103-29. This result concurs with the higher mortality rate for infections caused by EXA-producing $P$. aeruginosa strains in patients with leucopenia than in those without this condition. ${ }^{1}$ The greater virulence of $P$. aeruginosa PA103 seems likely to be due to the in-vivo 
production of EXA itself, considering that production of this toxin is the main difference from strain PA103-29.

We postulated that the greater virulence of strain PA103 might involve the action of EXA against PMNLs. EXA decreased the number of murine PMNLs in vivo, ${ }^{21}$ and killed murine and human PMNLs in vitro. Also, EXA inhibited the phagocytosis and killing of $P$. aeruginosa cells by PMNLs in vitro. Administration of MAb 3C7 antibodies against EXA inhibited the decrease in PMNL numbers caused by EXA in vivo and prevented death of the mice, whereas the non-homologous antibody, MAb 1B5, had no effect. Kohzuki et al. ${ }^{15}$ reported previously that administration of MAb $3 \mathrm{C} 7$ did not protect mice against bacteraemic death caused by $P$. aeruginosa 103. However, these authors only gave the antibody $2 \mathrm{~h}$ post-infection and, as the present study showed, protection against killing required that $\mathrm{MAb} 3 \mathrm{C} 7$

\section{References}

1. Cross AS, Sadoff JC, Iglewski BH, Sokol PA. Evidence for the role of toxin $A$ in the pathogenesis of infection with Pseudomonas aeruginosa in humans. J Infect Dis $1980 ; 142$ $538-546$

2. Dick JD, Shull V, Karp JE, Valentine J. Bacterial and host factors affecting Pseudomonas aeruginosa colonization versus bacteremia in granulocytopenic patients. Eur $J$ Cancer Clin Oncol 1988; 25: S47-54.

3. Young LS, Stevens P, Kaijser B. Gram-negative pathogens in septicaemic infections. Scand J Infect Dis 1988; Suppl 31: $78-94$.

4. Allured VS, Collier RJ, Caroll SF, McKay DB. Structure of exotoxin A of Pseudomonas aeruginosa at 3.0-Ångstrom resolution. Proc Natl Acad Sci USA 1986; 83: 1320-1324.

5. Pollack $M$, Young LS. Protective activity of antibodies to exotoxin A and lipopolysaccharide at the onset of Pseudomonas aeruginosa septicemia in man. J Clin Invest 1979; 63: 276-286.

6. Liu PV. Extracellular toxins of Pseudomonas aeruginosa. $J$ Infect Dis 1974; 130: S94-99.

7. Pollack M. The role of exotoxin A in Pseudomonas disease and immunity. Rev Infect Dis 1983; 5 Suppl 5: S979-S984.

8. Woods DE, Igrewski BH. Toxins of Pseudomonas aeruginosa: new perspectives. Rev Infect Dis 1983; 5 Suppl 4: S715-S722.

9. Gray GL, Smith DH, Baldridge JS et al. Cloning, nucleotide sequence, and expression in Escherichia coli of the exotoxin A structural gene of Pseudomonas aeruginosa. Proc Natl Acad Sci USA 1984; 81 : 2645-2649.

10. Hwang J, FitzGerald DJ, Adhya S, Pastan I. Functional domains of Pseudomonas exotoxin identified by deletion analysis of the gene expressed in E. coli. Cell 1987; 48: 129-136.

11. Lory S, Collier RJ. Expression of enzymic activity by exotoxin A from Pseudomonas aeruginosa. Infect Immun 1980; 28: 494-501.

12. Ohtsuki $\mathrm{H}$, Horigome $\mathrm{K}$, Higuchi $\mathbf{A}$ et al. Binding of monoclonal antibody specific for domain Ia/II of Pseudomonas aeruginosa exotoxin $\mathrm{A}$ at $\mathrm{pH} 4$ strongly neutralizes $\mathrm{A}$ induced cytotoxicity in cell culture and in vivo. Infect Immun 1992; 60: 1061-1068.

13. Singer SH, Ford M, Kirschstein RL. Respiratory diseases in was administered simultaneously with, or $2 \mathrm{~h}$ before, infection.

$P$. aeruginosa does make another toxin, termed cytotoxin or leucocidin, that is harmful to PMNLs, ${ }^{22}$ but this component was not detected in strains PA103 and PA103-29 by the methods of Hayashi ${ }^{23}$ and Hirayama in the present study. ${ }^{24}$ Furthermore the gene ( $c t x)$ encoding this toxin was not found by the colony hybridisation method (Hayashi, personal communication).

The toxicity of $P$. aeruginosa LPS is 2000 times lower than that of EXA in mice. ${ }^{6}$ In this study, LPS was detected at similar levels in the plasma of mice infected with either strain PA103 or PA103-29. These data argue against any role for LPS in the greater virulence of strain PA103, but an indirect relationship remains possible since the toxicity of the purified EXA in mice is apparently enhanced by simultaneous injection of LPS. ${ }^{25}$

cyclophosphamide-treated mice. I. Increased virulence of Mycoplasma pulmonis. Infect Immun 1972; 5: 953956.

14. Miyazaki S, Matsunaga T, Kawasaki K et al. Separate isolation of Clostridium difficile spores and vegetative cells from the feces of newborn infants. Microbiol Immunol 1992; 36: 131-138.

15. Kohzuki T, Eguchi $\mathrm{Y}$, Kato $\mathrm{M}$ et al. Protective activity of antiexotoxin A monoclonal antibody against mice infected with toxin-producing Pseudomonas aeruginosa. J Infect Dis 1993; 167: 119-125.

16. Obayashi T. Addition of perchloric acid to blood samples for colorimetric limulus test using chromogenic substrate: comparison with conventional procedures and clinical applications. J Lab Clin Med 1984; 104: 321-330.

17. Miyazaki S, Ohno A, Kobayashi I, Uji T, Yamaguchi K, Goto S. Cytotoxic effect of hemolytic culture supernatant from Enterococus faecalis on mouse polymorphonuclear neutrophils and macrophages. Microbiol Immunol 1993; 37: 265-270.

18. Ferrante A, Thong YH. Optimal conditions for simultaneous purification of mononuclear and polymorphonuclear leucocytes from human blood by the Hypaque-Ficoll method. J Immunol Methods 1980; 36: 109-117.

19. Bliss CI. The method of probits. Science $1934 ; 79$ : 38-39.

20. Ohman DE, Sadoff JC, Iglewski BH. Toxin A-deficient mutants of Pseudomonas aeruginosa PA103: isolation and characterization. Infect Immun 1980; 28: 899-908.

21. Hirakata Y, Furuya N, Tateda K, Kaku M, Yamaguchi K. In vivo production of exotoxin $A$ and its role in endogenous Pseudomonas aeruginosa septicemia in mice. Infect Immun 1993; 61 : 2468-2473.

22. Scharmann W. Formation and isolation of leucocidin from Pseudomonas aeruginosa. J Gen Microbiol 1976; 93: 283-291.

23. Hayashi T, Kamio Y, Terawaki Y. Purification and characterization of cytotoxin from the crude extract of Pseudomonas aeruginosa. Microb Pathog 1989; 6: 103-112.

24. Hirayama T, Kato I, Matsuda F, Noda M. Crystallization and some properties of leukocidin from Pseudomonas aeruginosa. Microbiol Immunol 1983; 27: 575-588.

25. Zehavi-Willner $T$. Induction of murine cytolytic $T$ lymphocytes by Pseudomonas aeruginosa exotoxin $\mathrm{A}$. Infect Immun 1988; 56: 213-218. 